\title{
O PEQUI COMO RECURSO DE USO COMUM E PATRIMÔNIO CULTURAL SERTANEJO
}

\section{PEQUI AS COMMON USE OF RESOURCE AND CULTURAL HERITAGE SERTANEJO}

\begin{abstract}
Marcos Nicolau Santos da Silva
Doutorando e Mestre em Geografia pela Universidade Federal de Minas Gerais - UFMG. Professor do Curso de Licenciatura em Ciências Humanas/Geografia da Universidade Federal do Maranhão UFMA/Campus de Grajaú. marcos.nicolau@yahoo.com.br

Maria Aparecida dos Santos Tubaldini Doutora em Geografia pela Universidade Estadual Paulista - UNESP/Rio Claro. Professora dos cursos de graduação e pós-graduação em Geografia pela Universidade Federal de Minas Gerais - UFMG. Coordenadora do Grupo de Pesquisa Terra \& Sociedade - IGC/UFMG. ubaldini1@uol.com.br
\end{abstract}

\section{RESUMO}

Este artigo tem como objetivo analisar o pequi como um recurso de uso comum e as relações de propriedade engendradas nos territórios dos cerrados do Norte de Minas Gerais e do Vale do Jequitinhonha, bem como propor que se considere o fruto como um patrimônio da cultura sertaneja. A metodologia utilizada baseou-se na pesquisa qualitativa, em que foram realizadas entrevistas com 15 famílias camponesas nos municípios de Campo Azul, Japonvar e Minas Novas, totalizando 45 famílias. Além disso, realizaram-se registros orais e escritos no diário de campo. Os resultados apontam que o pequi é considerado um recurso de uso comum entre as populações sertanejas. Seu uso extrapola o significado da propriedade privada. A maioria das famílias coleta o pequi em suas propriedades e nas propriedades vizinhas. Além dos aspectos materiais, reconhecidos pela sua intensa dinâmica econômica, o pequi tem grande impacto na vida cultural e simbólica de toda a população sertaneja. Pela sua relevância material e simbólica, o pequi e o pequizeiro podem ser considerados patrimônios culturais sertanejos.

Palavras-chave: Pequi. Pequizeiro. Recursos de uso comum. Patrimônio cultural sertanejo.

\footnotetext{
ABSTRACT

This article aims to analyze the pequi as a common use of resource and property relations engendered in the territories of the savannas of northern Minas Gerais and Vale of Jequitinhonha, as well as propose to consider the fruit as a heritage of sertaneja culture. The methodology used was based on qualitative research, where interviews were conducted with 15 peasant families in the municipalities of Campo Azul, Japonvar and Minas Novas, a total of 45 families. In addition, there were oral and written records in a field diary. The results show that the pequi is considered a common use of 
resources among the sertanejas populations. Its use goes beyond the meaning of private property. Most families collect the pequi on their properties and neighboring properties. In addition to the material aspects, recognized for its intense economic dynamics, pequi has great impact on cultural life and symbolic of the whole sertaneja population. Due to its material and symbolic importance, the pequi and pequizeiro can be considered cultural heritage sertanejos.

Keywords: Pequi. Pequizeiro. Common use of resources. Cultural heritage sertanejo.

\section{Introdução}

O extrativismo do pequi (Caryocar Brasiliense Camb.) é uma das mais importantes fontes de renda no Norte de Minas Gerais, sobretudo na economia informal. Também auxilia os camponeses de Minas Novas, no Vale do Jequitinhonha, que comercializam o fruto na feira da cidade. O pequi, além de produzir renda, produz cultura, visto que vários são os eventos regionais promovidos a partir desse fruto mais generoso de nossos Cerrados. É o caso da Festa Nacional do Pequi, ocorrida geralmente entre os meses de novembro e dezembro em Montes Claros; a Festa de São Sebastião, em Campo Azul, comemorada no mês de janeiro, auge da safra de pequi no município. Em Japonvar, não há festa na época do pequi, mas a cidade é considerada a Capital Nacional do Pequi e o fruto é referenciado na Festa do Biscoito entre junho e julho. Além disso, o pequi encontra-se nas músicas, poesias, lendas, histórias, arte e no artesanato regionais.

O Norte de Minas Gerais, indubitavelmente, é uma das regiões dos Cerrados que possui a maior importância no extrativismo do pequi. Tal importância não se configura apenas do ponto de vista econômico, mas também alimentar, cultural e ecológico. $\mathrm{O}$ material e o simbólico se interagem. O significado econômico do pequi é ao mesmo tempo cultural. O Vale do Jequitinhonha, nos Cerrados que lhe restam, também possui potencial produtivo de pequi, embora seja subexplorado.

O objetivo desse trabalho foi analisar o pequi como um recurso de uso comum e as relações de propriedade engendradas nos territórios dos cerrados do Norte de Minas Gerais e do Vale do Jequitinhonha, bem como propor que se considere o fruto como um patrimônio da cultura sertaneja.

Nossa questão matricial consistiu em saber se o pequi era considerado um recurso de uso comum nos territórios de estudo. Com as primeiras visitas prévias e o 
início dos trabalhos de campo, era possível responder à nossa questão central, a qual foi ganhando cada vez mais contornos à medida que entendíamos as práticas costumeiras e as relações simbólicas com o uso do território camponês do pequi. Território este que se revelou para além das cercas e do território-propriedade.

A base metodológica é a pesquisa qualitativa, na qual contou com a realização de entrevistas com famílias camponesas de três municípios mineiros, a saber: Campo Azul e Japonvar, no Norte de Minas Gerais; e Minas Novas, no Vale do Jequitinhonha. As entrevistas ocorreram em cinco comunidades rurais do município de Campo Azul e na comunidade Cabeceiras do Mangaí em Japonvar; em Minas Novas, as comunidades rurais selecionadas foram Cachoeira do Fanado e Cachoeira da Lagoa. Além disso, utilizamos ainda registros em diário de campo e relatos orais gravados.

\section{O pequi e os recursos de uso comum nos cerrados do Norte de Minas e do Vale do}

\section{Jequitinhonha}

Um artigo bastante conhecido quando se discutem os recursos naturais de uso comum é The Tragedy of the Commons, de Garrett James Hardin, escrito em 1968. O texto tornou-se referência obrigatória e se converteu em objeto de várias discussões de autores no fim do século XX, os quais se basearam nas observações de Hardin para elaborarem as suas. A Tragédia dos Comuns resgata as concepções de Malthus e discute o fracasso das soluções técnicas para problemas tipicamente humanos, diante de um contexto de crescimento exponencial da população e da corrida armamentista pós Segunda Guerra Mundial. Embora polêmica, o autor defende a tese de que a saída para a preservação dos recursos comuns é a privatização ou a definição como propriedades públicas, com concessão de direitos de acesso e uso. Apesar disso, ele declara "cada nova cerca no espaço comum envolve o infringir da liberdade pessoal de alguém" (HARDIN, 1968, p. 1248). Porém, a influência Malthusiana é muito forte para Hardin e ele conclui seu artigo dizendo:

A única maneira com que poderemos preservar e desenvolver mais e mais preciosas liberdades é abandonar a liberdade de procriação, e isto com brevidade. "Liberdade é o reconhecimento da necessidade" - e o papel da Educação é revelar a todos a necessidade de abandonar a liberdade de procriar. Somente assim poderemos dar fim à tragédia do espaço comum (HARDIN, 1968, p. 1248). 
Já que a temática da liberdade é abordada, Hardin, numa reflexão, conduz o leitor a imaginar uma pastagem comum em que cada criador tende a manter o maior número de cabeças de gado nesse espaço. Se seguir uma lógica racional, um criador pode aumentar o seu número de animais no pasto com o objetivo de ampliar seus ganhos, todavia essa lógica também é seguida pelos demais criadores. Assim sendo, estabelece-se a tragédia, pois cada criador receberia o lucro oriundo dos animais extras, compartilharia parte do custo da sobre-exploração das pastagens, e geraria uma perda de recurso para o total da comunidade de pecuaristas. Dessa forma, o autor concluiu: "a liberdade em relação a recursos comuns gera a ruína de todos" (HARDIN, 1968, p. 1244).

De acordo com Fenny et al. (2001, p. 18), "Hardin tem sido amplamente citado por ter afirmado que a degradação de recursos é inevitável, a não ser que a propriedade comum seja convertida em privada ou que normas governamentais a usos e usuários sejam instituídas". De certa forma, nosso programa de criação de unidades de conservação tem sido influenciado por tais acepções, apesar de isso ter provocado diversos conflitos entre as populações locais e os governos, cuja relação de apropriação e uso do território e dos recursos naturais tem sido desarticulada pela exclusão (ou desterritorialização) de seus habitantes para fora das unidades de conservação.

Por outro lado, a morosidade dos governos brasileiros (federal, estadual e municipal) em conciliar unidades de conservação com uso sustentável dos recursos naturais é um fator cada vez mais ameaçador da reprodução social das populações tradicionais do Cerrado. Uma das contradições existentes na criação das unidades de conservação de uso sustentável é que as reservas extrativistas aparecem em maior número na Amazônia e algumas das implantadas no Cerrado estão na fronteira com o domínio amazônico.

Recursos de propriedade comum incluem peixes, vida selvagem, águas superficiais e subterrâneas, pastagens e florestas. É importante delinear as características compartilhadas por esses recursos e distinguir entre recursos e regimes de direitos de propriedade nos quais os recursos são mantidos (NATIONAL RESEARCH COUNCIL, 1968 apud FENNY et al., 2001, p.19). 
Recursos de propriedade comum são, portanto, todos os bens naturais ou não a ser utilizados ou manejados de forma comum e coletiva, que possuem acesso limitado a um determinado grupo de usuários de direitos comuns, geralmente não sendo compartilhados a todos. Compreendem desde recursos naturais, como o pequi, as florestas, as águas etc., ou não, podendo ser uma estrada, ruas, entre outros.

De acordo com Mckean e Ostrom (2001, p. 80), “"propriedade comum’ ou 'regime de propriedade comum' referem-se aos arranjos de direitos de propriedade nos quais grupos de usuários dividem direitos e responsabilidades sobre os recursos". As autoras distinguem o termo "propriedade" do termo "recursos", pois o primeiro se refere a uma instituição social, enquanto o segundo compõe as partes do mundo físico ou biológico. Mckean e Ostrom (2001, p. 81) ainda apontam: “em regimes de propriedade comum, um grupo particular de indivíduos divide os direitos de acesso aos recursos, assim caracterizando uma forma de propriedade - ao invés de sua ausência”, ou seja, “existem direitos, e estes são comuns a um determinado grupo de usuários e não a todos".

Os casos estudados em Campo Azul, Japonvar e Minas Novas apontam para essa nítida separação entre o significado da "propriedade" e dos "recursos". Como "recurso", temos o pequi e os outros frutos nativos do Cerrado; como "propriedade", esta compreende tanto a propriedade fundiária - a terra - quanto os direitos de propriedade sobre os recursos, isto é, o direito de uso do pequi e dos outros produtos do Cerrado.

Diferente da propriedade fundiária, neste caso é a propriedade privada, a propriedade sobre o pequi não está, em geral, regida pela mesma lógica. A lógica da propriedade fundiária é individual e, portanto, é assegurado o direito de uso apenas ao(s) seu(s) dono(s). Mas o pequi não é regido apenas por essa lógica. Se na coleta ou no uso do pequi prevalecesse apenas a lógica da propriedade fundiária, seria um fracasso. O pequi está regido pelo predomínio da lógica costumeira, aquela ditada pelos seus próprios usuários. O sucesso ou não desse sistema comunitário de coleta/uso do pequi dependerá em boa parte da forma como será compartilhado pelos camponeses/usuários. É cabível a eles estabelecerem o controle de acesso de usuários e as regras de uso. 
O gráfico 1 aponta os diferentes locais onde os camponeses coletam o pequi nos territórios estudados. Ficou evidente na pesquisa que todos os territórios de coleta são propriedades particulares, mas isso não impede o trabalho dos camponeses. Assim sendo, a mesma família camponesa que coleta o pequi em sua própria propriedade também o faz nas propriedades de parentes e vizinhos, sem, na maioria das vezes, implicar algum impedimento.

GRÁFICO 1 - Locais de coleta do Pequi

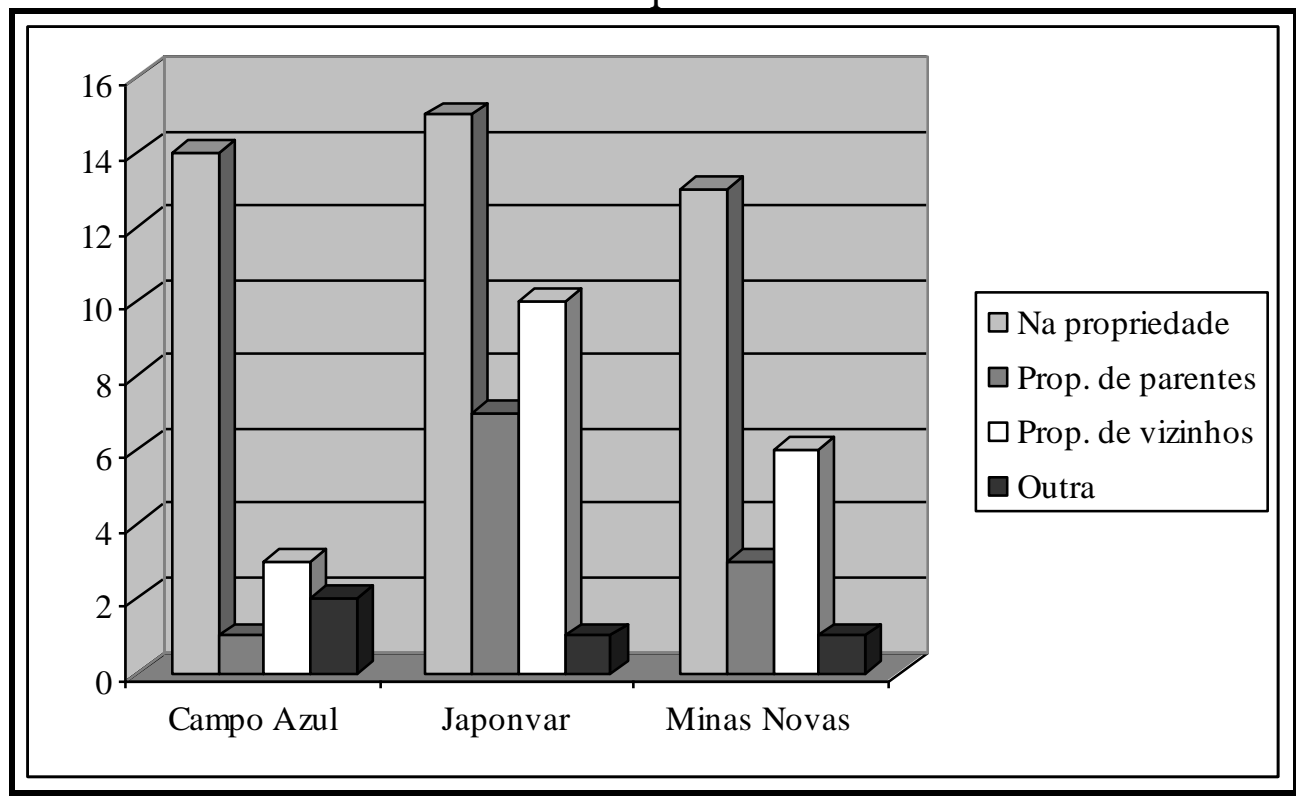

Fonte: Pesquisa de Campo, 2010.

As informações apoiadas apenas num gráfico não revelam como se dão as outras formas de organização e de tramas sociais da coleta do pequi. Consoante o gráfico mostra, a quase totalidade de famílias entrevistadas coleta o pequi na sua própria propriedade, sendo que algumas famílias não possuem pequizeiros em sua propriedade e/ou moram em terras de outrem. Os dados do gráfico para Japonvar mostram uma intensidade maior nas áreas de coleta em relação às outras localidades. O sistema comunitário de acesso e uso do pequi impõe menos restrições à comunidade Cabeceiras do Mangaí. Resumindo, a organização social e comunitária, inicialmente, se foi mais importante do que a lógica do dinheiro. O sistema comunitário do pequi, portanto, organizou-se baseado na lógica costumeira, considerando as relações comunitárias, de parentesco e vizinhança, de forma que o recurso natural, nativo, se expressa como um "bem comum" e, por consequência, de uso "coletivo", independente do significado da 
propriedade. Isso não implica, porém, que esteja isento de conflitos comunitários. Vejamos a fala de um camponês, a qual vai apontar as relações comunitárias e, às vezes, conflitivas, em Japonvar:

\begin{abstract}
Por acaso, eu posso sair daqui e entrar na terra de uma pessoa pra panhar pequi, chegando encontro com o dono panhando também, nós bate papo de dois, depois torna sair um pra um canto o outro pro outro... é comum. É, fruto do cerrado aqui... inclusive ainda tem algumas pessoas aqui que xinga o povo, mas é pessoa que é ruim vizinho e tudo. Mas, a maioria ninguém xinga ninguém por 'mode' (causa de) pequi não (Camponês, 46 anos, Cabeceiras do Mangaí).
\end{abstract}

Nos territórios rurais de Minas Novas, não é muito diferente. Nestas localidades, a tirania do dinheiro, conforme Santos (2006), "ainda" não penetrou. O aproveitamento econômico do pequi nestas comunidades, e por que não dizer, também nas outras áreas de Cerrados do Vale do Jequitinhonha, "ainda" não se "despertou”, como em Japonvar e Campo Azul. Além disso, o mercado consumidor das cidades locais da região é limitado. Em Minas Novas, por exemplo, consoante mostramos no início deste trabalho, a maior parte da população vive no meio rural, o que significa ter uma maior facilidade de acesso a recursos naturais como o pequi. O comércio do pequi em Minas Novas é na feira, a qual comporta uma economia mercantil simples - terminologia adotada por Marx e interpretada por Moura (1986) - e relações sociais importantes no cotidiano do camponês e do citadino. Enquanto o pequi é vendido, pelos camponeses, em medidas de caixas contêineres e sacarias para comerciantes ou atravessadores no Norte de Minas, aqui é vendido em pequenas medidas, sobretudo nas feiras, diretamente ao consumidor final.

Contudo, Minas Novas e outras áreas do Vale do Jequitinhonha não estão imunes à penetração de um dinheiro mais tirano, em sua forma mais capitalista e global. O comércio de pequi, cujas relações sociais e as formas de troca são simples, pode dar lugar, a relações capitalistas mais complexas como no Norte de Minas. Até então, aqui, o território rege o dinheiro, e este é um dinheiro mais local. Temos, assim, um território usado por uma sociedade localizada, onde as relações de uso são mais importantes que as de troca (SANTOS, 2006).

Pelo exposto, em Cachoeira do Fanado e Cachoeira da Lagoa, os camponeses costumam coletar o pequi apenas na sua propriedade, pois, se o consumo local é menor, 
não há necessidade de catar o fruto na propriedade vizinha. Só se cata o pequi do vizinho caso sua terra não possua ou tenha poucos pequizeiros. Ademais, existe o costume de coletar no vizinho quando se vai fazer uma maior quantidade de óleo naquele ano ou se estiver desperdiçando o fruto. Assim, o sistema comunitário é organizado semelhante ao de Japonvar, onde as famílias podem coletar o pequi umas nas terras das outras, sem conflitos.

As propriedades rurais em Campo Azul são maiores em relação aos outros municípios pesquisados, até mesmo as camponesas. Muitas propriedades são grandes fazendas de criação de gado, especialmente pelo fato de as chapadas não possuírem solos adequados à prática agrícola. Algumas propriedades se tornam improdutivas, pois a criação de gado e a ostentação de ter muita terra definem um status social e patrimonial da classe dos fazendeiros. Da mesma forma, existem muitos camponeses cujas terras são extensas, oriundas de um antigo processo histórico de posse da terra, nas quais plantam suas roças, criam seus animais, especialmente o gado, e fazem coleta de frutos do Cerrado, principalmente o pequi. Outros proprietários de grandes extensões de terras, sem interesse nem necessidade de coletar pequi, arrendam suas chapadas durante a safra em Campo Azul para camponeses locais ou de outras localidades. Alguns desses proprietários também costumam contratar os serviços de outros camponeses para "pegar pequi na meia".

As formas como é realizada a coleta do pequi são baseadas no sentido da propriedade da terra. Em Campo Azul, a propriedade fundiária influencia no sistema comunitário de coleta do pequi. Aqui, as formas de se extrair a renda da terra arrendamento e meação - subordinam a coleta do pequi e, consequentemente, a lógica camponesa. Assim, a lógica do dinheiro e do capital impõe-se sobre a lógica costumeira, sem eliminá-la, porém transformando-a.

Mesmo havendo algumas relações sociais comunitárias na coleta do pequi em Campo Azul, conforme aponta o gráfico 1, o significado da "propriedade fundiária" não elimina o sentido da "propriedade do recurso". Alguns camponeses afirmaram não impedir a coleta de pequi por alguns vizinhos, principalmente quando é destinado ao consumo. A maior objeção é quando as pessoas panham o pequi para vender, já que eles também precisam aproveitá-lo na renda. A diferença quando comparamos com a coleta em Japonvar é que neste município, mesmo que todos vendam, não há impedimento de 
um catar pequi na terra do outro. A coleta tem mais a função de unir os "iguais" do que propriamente a função de separá-los, pois o pequi que ajuda uma família também é o mesmo que ajuda ao seu vizinho.

A fim de entendermos melhor os diferentes tipos de direitos de propriedade, Fenny et al. (2001) definiram quatro categorias no âmbito das quais os recursos de propriedade comum são manejados: livre acesso, propriedade privada, propriedade comunal e propriedade estatal. O primeiro diz respeito à ausência de direitos de propriedade bem definidos, ou seja, o acesso aos recursos não é regulado, sendo livre a qualquer pessoa. Um exemplo é a atmosfera global, cuja propriedade é indefinida, portanto sujeita à extrema degradação.

Sobre a propriedade privada, os direitos de exploração e regulação dos recursos são cedidos a indivíduos ou grupos, como as empresas. No regime de propriedade privada, há a exclusão de terceiros, normalmente a concessão do uso é feita pelo Estado. Podemos exemplificar através das terras devolutas do estado de Minas Gerais, cuja exploração foi concedida a empresas de reflorestamento com eucalipto na década de 1970.

No regime de propriedade comunal, os recursos são manejados por uma comunidade identificável de usuários interdependentes. Geralmente, os usuários excluem a ação de indivíduos externos, ao mesmo tempo em que regulam o uso por membros da comunidade local. Neste caso, os usuários podem utilizar as áreas comunais de pastagens nativas das chapadas do Norte de Minas Gerais para criação de gado, situação que era muito comum na região, ou mesmo coletar frutos nativos nestas áreas: o pequi, o panã, a cagaita, a mangaba, a pitomba, a siriguela, o umbu, o coco macaúba, etc. O exemplo da coleta de pequi nos Cerrados norte mineiro e do Vale do Jequitinhonha pode exemplificar bem o que significa um recurso de propriedade comunal.

Em áreas rurais onde há mobilização de seus membros, como no exemplo do município de Japonvar, as famílias coletam o pequi destinado à comercialização no interior de suas propriedades ou de seus parentes e vizinhos. É importante pensar que o pequizeiro, presente em quase todo o Cerrado mineiro, é nativo, configurando-se então como um recurso "comum”. Então, supomos que o seu aproveitamento seja de todos. Entretanto, contraditoriamente, esse mesmo recurso está sob a égide da propriedade 
privada da terra, significa que ele só pode ser coletado/usado mediante a autorização dos proprietários da terra (Gráfico 2).

GRÁFICO 2 - Regulação da coleta de Pequi.

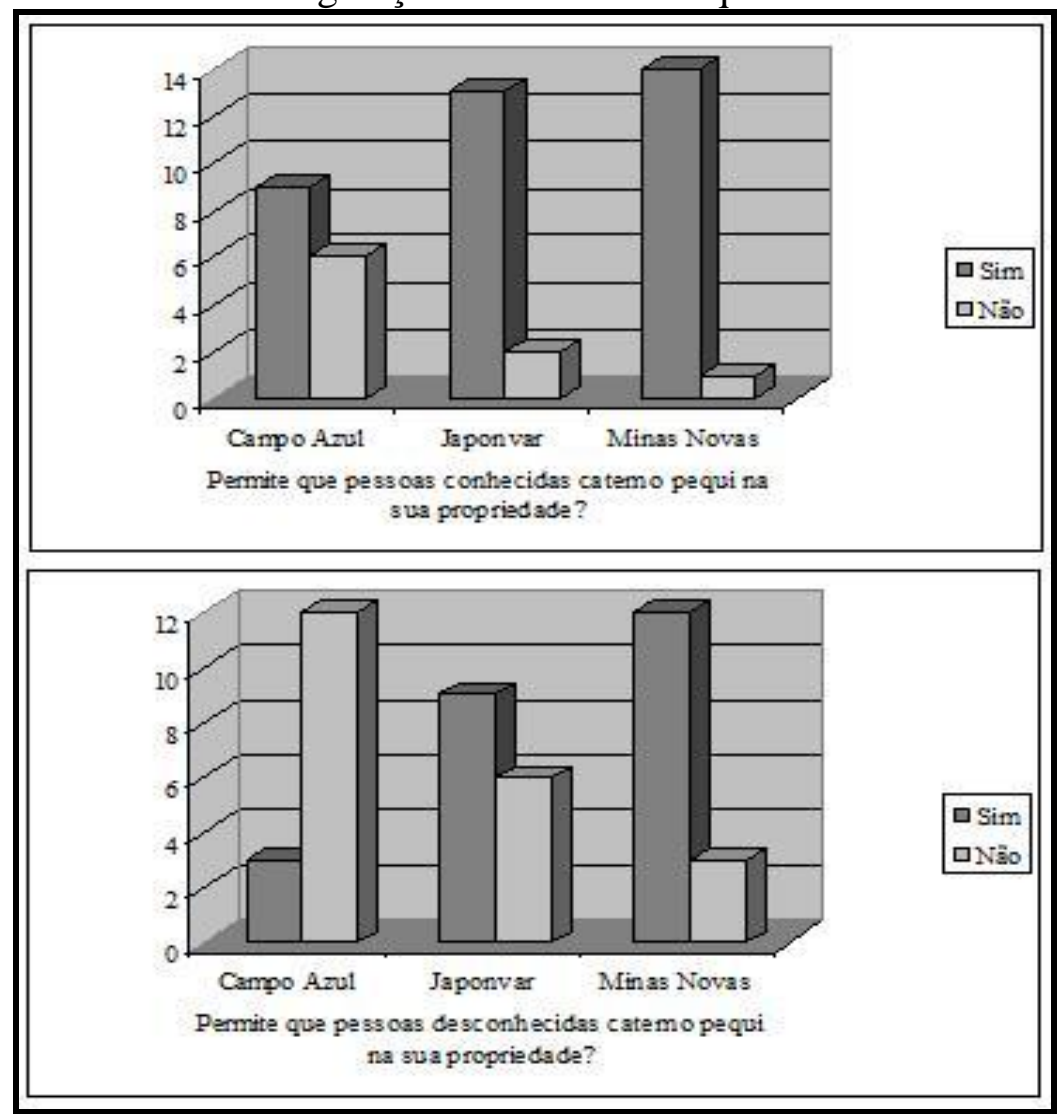

Fonte: Pesquisa de Campo, 2010.

O gráfico 2 apresenta duas situações investigadas na nossa pesquisa. A primeira almeja saber do consentimento das famílias camponesas na coleta do pequi em suas propriedades por pessoas conhecidas, normalmente da comunidade rural. Como se pode observar no gráfico, poucas famílias em Japonvar e Minas Novas não autorizam, ou pelo menos não gostam, que outras pessoas das comunidades catem o pequi em suas terras. A maioria dos camponeses tem a certeza- o consentimento simbólico- de que o pequi foi "Deus [quem] deixou para todo mundo. Não foi ninguém que plantou, né? Tem que ser para todo mundo" (Camponesa, 49 anos, Japonvar).

Quanto à questão de direito de propriedade, os camponeses entendem que o pequi seja [ou deva ser] comum: "não foi a gente que plantou, só porque está no terreno da gente não é só da gente" (Camponesa, 46 anos, Cachoeira do Fanado). O importante é que o resultado da coleta do pequi traz valorosos significados para os camponeses, 
como este: "porque aqui e acolá a gente panha deles também; a comunidade aqui é toda unida" (Camponês, 64 anos, Japonvar).

Em Campo Azul, pouco mais da metade das famílias camponesas (9 famílias) permite a coleta do pequi em sua propriedade por pessoas conhecidas da comunidade. A minoria dessas (6 famílias) só permite se for para consumo ou no início da safra, quando os caminhões ainda não começaram a carregar.

$\mathrm{Na}$ segunda situação, buscamos saber se as famílias camponesas também permitem a coleta do fruto a pessoas desconhecidas da comunidade. Em Campo Azul, a maior parte das respostas foi negativa. Em Japonvar e Minas Novas, predominaram as respostas afirmativas. Neste caso, o motivo que justifica a permissão da coleta por pessoas desconhecidas também é a gratuidade do pequi.

Outra observação é que o pequi só está apto para a coleta após cair no chão, e os proprietários da terra normalmente não permitem a coleta do fruto quando ainda está na árvore. Por unanimidade, todas as famílias camponesas entrevistadas responderam que só catam os pequis do chão. Também afirmaram não permitir outras pessoas derrubarem os pequis ou baterem vara no pequizeiro. Apesar disso, no final da safra, quando os caminhões não mais retornam para compra, alguns camponeses, durante as entrevistas, disseram que tem pessoas que colhem os pequis diretamente do pequizeiro, abandonando a prática usual da coleta no chão que não estraga as árvores do pequi.

Um fato interessante, ocorrido quando fomos até Japonvar no mês de novembro de 2010, para verificar o início da safra de pequi, foi que, enquanto conversávamos com uma família camponesa, de repente uma criança gritou o seu tio desesperadamente porque havia alguém na comunidade derrubando os pequis. Tal fato reforça a tradição de uma geração a outra entre as populações sertanejas que dependem do pequi e dos outros recursos naturais dos Cerrados, e assegura a lógica costumeira de que seus próprios membros devem estabelecer as formas de regulação do uso dos recursos do território. Dessa forma, os recursos sob o regime da propriedade comunal podem sofrer regulação dos membros de suas comunidades.

Por fim, na propriedade estatal, os direitos aos recursos são alocados exclusivamente no governo, o qual, por sua vez, toma decisões em relação ao acesso a eles e ao nível e natureza da exploração. O Estado tem controle do acesso e do uso dos recursos, já que o mesmo possui poderes coercitivos de imposição, ao contrário de 
grupos privados. O que é de propriedade estatal implica que o público tem acesso e direitos iguais, tais como rodovias e visitação a parques públicos.

Goldman (2001) aponta que, a partir da tese de Hardin, surgiu a escola "antitragédia", composta por um grupo de cientistas políticos, ecólogos, antropólogos, sociólogos e economistas apresentando argumentos contrários, os quais são, em grande parte, baseados em pesquisas empíricas. Segundo eles, a tese da tragédia é peca pela ausência de veracidade histórica, teórica e cultural.

Goldman organiza essa escola em três tendências principais. Uma é composta por Ecólogos Humanos, os quais demonstram a complexidade dos comuns através de uma perspectiva baseada na cultura e na territorialidade. Outra tendência vem dos Especialistas em Desenvolvimento, que, de forma pragmática, mostram como recuperar os comuns degradados, fortalecer as instituições sociais enfraquecidas e "modernizar" os pobres países subdesenvolvidos. A terceira são os Gerentes de Recursos Globais, os quais descrevem como os comuns não se constituem somente em problemas de escala local ou associados a povos desprivilegiados, mas que também contribuem para a crise ecológica global. Esta última está bastante em evidência atualmente devido ao alarme em torno do aquecimento global.

Os Especialistas em Desenvolvimento têm sido a tendência mais atuante já há algum tempo, pela sua inserção nas políticas de desenvolvimento nos países desenvolvidos e em desenvolvimento. Já os Ecólogos Humanos, apesar de recentes, apresentam-se como uma tendência em expansão pela emergência das territorialidades humanas mais específicas, com um forte viés cultural.

Thompson (1998), baseando-se no sistema comunitário de uso dos recursos comuns na Inglaterra entre os séculos XVII e XVIII, mostra-o organizado mediante os costumes locais. O autor em questão afirma:

Se todas as terras agrícolas da Inglaterra e do País de Gales tivessem tão sujeitas a ações predatórias quanto as florestas régias ou tão acossadas por disputas como Charnwood, teriam servido como provas ilustrativas das teses sombrias de Garrett Hardin (THOMPSON, 1998, p. 93).

Para Thompson, os argumentos de Hardin de que ninguém possui e protege os recursos comuns levaria a uma inexorável lógica econômica que os condena à superexploração. O autor destaca também que o que Hardin negligencia é que os 
próprios commoners, como ele se refere aos plebeus ou homens comuns do período em questão na Inglaterra, não eram desprovidos de bom senso. "Ao longo do tempo e do espaço, os usuários das terras comunais desenvolveram uma rica variedade de instituições e sanções comunitárias que impôs restrições e limites ao uso" (THOMPSON, 1998, p. 93).

De acordo com Diegues (2001, p. 97):

\begin{abstract}
Os sistemas tradicionais de acesso a espaços e recursos de uso comum (comunitário) existentes no Brasil não são formas do passado, congeladas no tempo ou em total desorganização frente ao avanço da propriedade privada. Ainda que muitos desses sistemas tenham-se desestruturado frente à expansão capitalista, existem exemplos recentes que mostram a capacidade dos “comunitários" não só em reagir, mas também em reorganizar-se, recriando modos de vida e territórios de uso comum.
\end{abstract}

O sistema comunitário no Brasil não teve as mesmas características da Europa, pois, desde o início, a colonização transformou as terras em bens de capital. Entretanto, comungando com as observações de Thompson, podemos afirmar que o próprio sistema comunitário do pequi, como um recurso comum, mostra-se contrário à tese de Hardin. Neste caso, mesmo o pequi estando fundamentalmente assentado sobre a égide da propriedade privada, ele continua sendo um recurso comum e compartilhado, cujas restrições e limites de uso, impostos pelas comunidades estudadas, regulam o sistema comunitário e têm se mostrado, até então, eficiente na preservação dos bens comuns.

Contrariamente à tese fatídica da tragédia dos comuns, nos casos por nós estudados, o sistema comunitário não se apresenta como predatório dos recursos naturais. Pelo contrário, os recursos que se encontram "privatizados" são levados a uma maior degradação devido à expansão da fronteira agrícola, das monoculturas de reflorestamentos, enfim, dos empreendimentos capitalistas. Ademais, vale frisar, recursos naturais transformam-se em diversos conflitos sociais quando estão sob a tutela do Estado.

\title{
O pequi como patrimônio cultural sertanejo
}

As ideias seguintes apresentam algumas noções sobre um dos principais recursos naturais, o qual, no nosso entender, faz parte do patrimônio sertanejo - o pequi. 
O patrimônio é um conceito há muito tempo presente na nossa sociedade. Falamos do patrimônio pessoal, de uma família, de uma empresa, de um povo, de um país, da humanidade, etc. Amazônia, patrimônio da humanidade! Por que não falarmos também dos Cerrados como patrimônio do povo brasileiro?

Serrano (2007, p. 9) escreve um trabalho no qual suas primeiras palavras são: “ $O$ patrimônio está morto. Viva o patrimônio!". Suas palavras são uma aclamação, um convite ao debate, pois parece ser esta a ideia expressada pela noção de patrimônio na contemporaneidade. Precisamos falar da "morte" do patrimônio para depois falar de sua reinvenção. Assim como diversos outros conceitos bastante conhecidos no meio acadêmico, segundo a autora, "a 'morte' do patrimônio pode ter ocorrido, paradoxalmente, pela modernidade, que o inventou e depois lhe roubou os sentidos".

A própria modernidade desconstruiu e desprezou a memória do passado, visto e tratado como arcaico e não moderno. Toda a memória, todo o patrimônio do passado, os quais antes pareciam ameaçados, agora renascem fortalecidos. Nesse sentido, Abreu e Chagas (2003) afirmam que o patrimônio cultural no Brasil está vivendo um momento novo. Isso, porém, parece não ter limites para estabelecer a noção e os domínios do patrimônio. O patrimônio contempla desde bens materiais, como igrejas, fortes, prédios, até os bens simbólicos, a despeito do badalar dos sinos, do registro de festas, saberes e fazeres (SERRANO, 2007).

De acordo com Gonçalves (2003), a categoria patrimônio não é apenas uma invenção moderna, ela é milenar; está presente no mundo clássico e na Idade Média. Ela também está presente em sociedades tribais e tradicionais. Para o autor, essa categoria de pensamento é extremamente importante na vida social e mental de qualquer coletividade humana.

Gonçalves (2003) e Abreu (2003) declaram que a noção de patrimônio confunde-se com a de propriedade. Isso é facilmente verificado entre os camponeses. Mas, quando percebemos o sentido de recurso de propriedade comum, o pequi extrapola o significado de propriedade e se torna um patrimônio comum.

Conforme Serrano (2007), produzir o passado significa a produção de uma memória individual ou coletiva. Quando pensamos no pequi, atribuí-lhe uma qualidade de patrimônio cultural sertanejo, significa restituí-lo de todo um valor, reconhecendo o seu passado e aceitando sua importância como recurso de uso e troca das populações 
sertanejas, mas também significa assegurar-lhe seu futuro como recurso natural, histórico, econômico, social e cultural.

Com efeito, comungamos com Abreu (2003), quando a autora menciona que, se outrora o campo do patrimônio teve como base o Estado nacional, resgatando a ideia de que a nação tinha um passado e este era preciso ser resgatado do esquecimento, atualmente o patrimônio estrutura-se de maneira prospectiva em direção ao futuro. A palavra de ordem para a autora é "diversidade" - diversidade cultural, natural, etc.

Ao fazer tal análise, estamos resgatando o sentido de valor natural e humano ao pequi e sua árvore, tão ameaçados pela degradação e pela modernidade nos Cerrados. Estamos, portanto, assegurando as tradições, os gostos, os saberes, os fazeres e os sabores, e também o significado das festas, da cultura regional, da arte e do artesanato inspirados no fruto sertanejo.

O patrimônio cultural brasileiro é entendido segundo a Constituição Federal de 1988, artigos 215 e 216, como todos:

\footnotetext{
Os bens de natureza material e imaterial, tomados individualmente ou em conjunto, portadores de referência à identidade, à ação, à memória dos diferentes grupos formadores da sociedade brasileira, nos quais se incluem: I. as formas de expressão;

II. os modos de criar, fazer e viver;

III. as criações científicas, artísticas e tecnológicas;

IV. as obras, objetos, documentos, edificações e demais espaços destinados às manifestações artístico-culturais;

V. os conjuntos urbanos e sítios de valor histórico, paisagístico, artístico, arqueológico, paleontológico, ecológico e científico (BRASIL, 2003 apud FONSECA, 2003, p. 59-60).
}

Somente no ano 2000, por meio do Decreto 3.551, de 4 de agosto, "institui o Registro de Bens Culturais de Natureza Imaterial, que constituem patrimônio cultural brasileiro, cria o Programa Nacional de Patrimônio Imaterial e dá outras providencias". Além disso, esse registro é constituído em quatro livros, conforme os incisos: "I - Livro de registro de saberes; II - Livro de registro das celebrações; III - Livro de registro das formas de expressão; IV - Livro de registro dos lugares” (OLIVEN, 2003, p. 78).

De acordo com Oliven (2003, p. 77), o termo "patrimônio" (heritage, em inglês) refere-se a algo que herdamos e que deve ser protegido. Para ele, isso implica que o processo de "congelamento" está sempre presente na ideia de patrimônio, mostrando que um bem, material ou imaterial, para que seja preservado, deve-se mantê-lo intacto. 
Se considerarmos o óleo de pequi, por exemplo, ao registrá-lo no livro de saberes, seu processo culinário deveria ser mantido intacto. Porém, as formas de preparar os alimentos não se modificam ao longo do tempo? O óleo de pequi é um alimento, logo ele é material, mas a sua culinária, seu modo de fazer são imateriais. Nesse sentido, “os 'bens imateriais' não só são de difícil definição, mas também só têm sentido se significarem uma prática regular" (OLIVEN, 2003, p. 79).

Acerca do pequizeiro, sua importância está assegurada desde a Portaria 54, de 05 de março de 1987, do Instituto Brasileiro de Desenvolvimento Florestal (IBDF), a qual impede seu corte e a comercialização de sua madeira. Também está ratificada na Portaria ${ }^{\circ}$ 113, de 29 de dezembro de 1995, do Instituto Brasileiro do Meio Ambiente e dos Recursos Renováveis - IBAMA (MACEDO, 2005).

Em Minas Gerais, o pequizeiro e seu fruto recebem tratamento especial, pelo menos sua preservação está prevista em lei. A Lei 13.965, de 27 de julho de 2001, regulamentada pelo Decreto 42.646, de 05 de junho de 2002, criou o Programa Mineiro de Incentivo ao Cultivo, à Extração, ao Consumo, à Comercialização e à Transformação do Pequi e demais Frutos e Produtos Nativos do Cerrado - PRÓ-PEQUI. Assim sendo, em seu Artigo $1^{\circ}$, a lei objetiva "integrar as populações que tradicionalmente exploram o cerrado no uso e manejo racional desse bioma, numa perspectiva de sustentabilidade ambiental" (MINAS GERAIS, 2001). No Artigo $2^{\circ}$ da referida lei, alguns pontos devem ser observados nos incisos:

I - identificar as áreas de incidência de comunidades tradicionais que vivam ou sobrevivam da coleta do pequi e de outros produtos nativos do cerrado; III - realizar estudos visando à recuperação da biodiversidade das terras públicas e devolutas localizadas em áreas do cerrado retomadas pelo Estado que tenham sido objeto de contratos de arrendamento ou comodato ou outros instrumentos congêneres e utilizadas em projetos agrossilvipastoris;

IV - criar mecanismos que assegurem a utilização, pelas comunidades tradicionais, organizadas em cooperativa ou outra forma associativa, de áreas de reserva legal para a coleta de frutos e produtos nativos do cerrado; VI - pesquisar os aspectos culturais e folclóricos relacionados com o pequi e demais frutos do cerrado, divulgar seus eventos comemorativos e datas relevantes e identificar, dentro do programa, as áreas adequadas ao turismo e incentivar sua prática;

VIII - incentivar a industrialização do pequi e demais frutos do cerrado, mediante sua transformação em doces, licores, batidas e outros derivados;

Diante do exposto, vale frisar, entre os artigos e incisos destacados pela lei Própequi, que muito necessita avançar. Até então, verificamos e percebemos com as 
entrevistas, que tem ocorrido uma maior fiscalização ambiental para impedir o abate aos pequizeiros. No entanto, vale lembrar, as próprias populações sertanejas também realizam a proteção da planta por meio dos seus costumes locais.

Torna-se imprescindível que o programa Pró-pequi deixe o papel e possa criar alternativas para as populações dos Cerrados de Minas Gerais. Consoante está previsto na lei e acima supracitado, uma importante ação seria a disponibilização das terras públicas e devolutas que ainda se encontram principalmente sob o domínio das empresas de reflorestamento com eucalipto e pinus. Tornar tais terras eco-produtivas, com base em modelos agroextrativistas e pastoris sustentáveis, é de fundamental importância para as comunidades, as quais tanto esperam pela apropriação de seus antigos territórios de uso.

Nas terras das chapadas de Minas Novas ocupadas por eucalipto, mesmo a lei proibindo a retirada dos pequizeiros que rebrotaram, ainda assim o extrativismo se torna uma impossibilidade, já que o sombreamento compromete o desenvolvimento da planta. Tais terras podem ser aproveitadas para a reconversão agroextrativista, sob a posse camponesa, devolvendo o território aos sertanejos e melhorando as condições socioambientais locais.

Retomando a questão anterior, a própria interpretação da legislação mineira torna o pequi e sua árvore patrimônios materiais do estado. Os aspectos naturais e econômicos inerentes ao pequi convertem-no num valioso recurso, imbuído de grande capacidade de assegurar a sobrevivência de muitas famílias sertanejas no Norte de Minas e Vale do Jequitinhonha. Por isso, carece de maior incentivo, divulgação e projetos baseados no potencial de aproveitamento de seus recursos naturais, a começar pelo pequi.

Além dos aspectos materiais, o patrimônio intangível (imaterial) do pequi é diverso. A culinária regional com o fruto deve ser destacada pelos seus doces, licores, óleo, o arroz com pequi, o frango com pequi. Além disso, em Montes Claros (Norte de Minas), há anualmente a tradicionalidade da Festa Nacional do Pequi, a qual valoriza o fruto mais generoso de nossa cultura popular e coloca em questão a problemática ambiental envolvendo o pequi e os Cerrados através de oficinas e palestras temáticas.

Há também em Montes Claros o fervor da criação de um time de vôlei, que leva 
o nome da cidade e disputa competições esportivas de âmbito nacional, conhecido popularmente como "Pequi Atômico", divulgando assim o fruto e a cultura regional.

Podemos falar ainda do pequeno município de Japonvar, onde realizamos nossa pesquisa. Nessa localidade, a vida das pessoas gira em torno do pequi, durante e depois da safra. O pequizeiro aqui é, metaforicamente, um ente da família pela sua relevância na vida dessas pessoas. Como dizem os próprios camponeses: "é festa no tempo de pequi em Japonvar”. Para quem pensa ser o pequizeiro encontrado somente no cerrado, surpreende-se quando o encontra no quintal das casas das pessoas, na praça, enfim, na vida dos sertanejos (Foto 1). Sendo assim, perguntamos: o pequizeiro precisa ser domesticado? Ele não é um patrimônio cultural do povo norte mineiro, ou quiçá, do Vale do Jequitinhonha?

FOTO 1 - O pequizeiro na vida das pessoas - cidade de Japonvar.

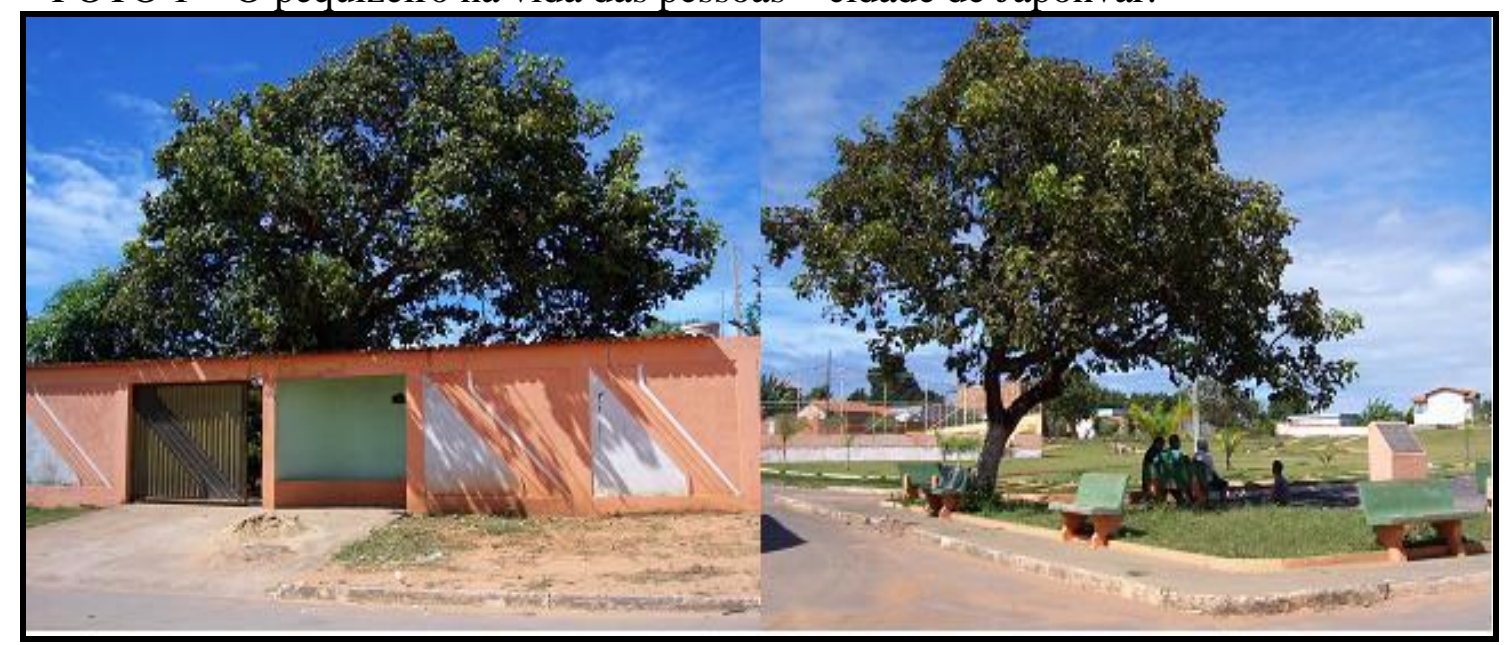

Fonte: Pesquisa de campo, 2010.

Japonvar também se desponta com a criação da Lei Municipal $n^{\circ}$ 96, a qual entrou em vigor desde janeiro de 2004. O primeiro artigo da lei contempla uma reivindicação constante entre os camponeses, a proibição da retirada antecipada do fruto, e o segundo artigo ratifica a legislação nacional, imunizando o pequizeiro de corte:

Art. $1^{\circ}$ - Fica proibida, na área de jurisdição do Município de Japonvar, a colheita/retirada antecipada de frutos do pequizeiro que ainda não tenha atingido seu ponto de maturação completo, definida deiscência do fruto no chão, ou queda do mesmo, sem utilização de varas, escadas e outros meios que forcem a sua derrubada. 
Art. $2^{\circ}$ - Fica declarado como de preservação permanente e de interesse comum e imune de corte no Município de Japonvar o Pequizeiro (Caryocar Brasiliense).

Para a execução desses dois artigos, o artigo terceiro compete grande responsabilidade à Polícia Florestal (Polícia do Meio Ambiente), a quem "cabe a fiscalização, apreensão, multa e prisão dos infratores". Além disso, o artigo quarto faz um chamamento à participação da população rural e das associações comunitárias para preservar o pequizeiro e a coleta de seus frutos por meio de denúncias (JAPONVAR, 2004).

Por apresentar valores ecológico, econômico, social, alimentar, simbólicocultural, o pequi, o pequizeiro e o óleo de pequi poderiam estar registrados nos livros do patrimônio cultural do IPHAN - Instituto do Patrimônio Histórico e Artístico Nacional, já que todos os nossos camponeses entrevistados em Campo Azul, Japonvar e Minas Novas reconheceram o pequi como símbolo da cultura local ou regional. Tal reconhecimento já havia, entretanto, sido atestado em um concurso popular realizado pelo Instituto Estadual de Florestas (IEF) no ano de 2001, no qual elegeu o pequizeiro símbolo do estado de Minas Gerais.

Nesse sentido, um patrimônio cultural valorizado é aquele que, primeiro, é reconhecido e identificado pelos seus próprios sujeitos como parte de sua identidade:

\footnotetext{
A valorização do patrimônio cultural depende necessariamente do grau de conhecimento que se tem de suas inúmeras e diversificadas formas de utilização. Sua preservação, da consciência e do orgulho com que os grupos sociais o amparam e guardam como elemento da própria identidade (DELPHIM, 2004, p. 4).
}

Sobre os vários valores materiais e imateriais do pequi e do pequizeiro, reconhecidos na cultura sertaneja mineira, concordamos com Dematteis (2007, p. 10) quando ele afirma: "não entendemos somente os valores de mercado, mas também e, sobretudo, os recursos ecológicos, humanos, cognitivos, simbólicos, culturais que cada território pode oferecer como valores de uso, bens comuns, patrimônio da humanidade".

\section{Considerações finais}


A pesquisa nos permitiu constatar que o pequi é considerado um recurso de propriedade comum entre as populações sertanejas analisadas. Sua coleta extrapola o significado das cercas que cerceiam as propriedades. Isso implica que a coleta do fruto pode ser realizada sem que a propriedade (privada) seja um empecilho. O território de coleta do pequi é aberto, pois não se limita apenas ao território-propriedade.

O sistema de coleta do pequi nos territórios estudados se organizou baseado na lógica costumeira, considerando as relações comunitárias, de parentesco e vizinhança, de modo que o recurso natural é entendido como um "bem comum", portanto, seu uso é coletivo, independente do significado da propriedade. Isso não significa dizer que não haja conflitos comunitários. O pequi é comum porque não foi plantado, nem exigiu esforço dos camponeses, embora eles cuidam e zelam pelos pequizeiros. É entendido como uma dádiva da natureza.

Em Japonvar, o sistema de coleta do pequi não impõe muitas restrições aos catadores, pois eles coletam o fruto em suas propriedades e nas de outrem. De forma semelhante, em Minas Novas o pequi também é coletado em várias propriedades, mas, como o consumo e a venda são pequenos, não há necessidade em catar o fruto em outras propriedades. Há a coleta em outras propriedades, de parentes e vizinhos, apenas quando uma família irá fazer uma quantidade maior de óleo de pequi para a venda.

A coleta do pequi em Campo Azul é um pouco diferente, pois aqui há certas restrições. Os camponeses revelaram que não permitem que pessoas estranhas à comunidade catem o pequi em suas terras. Já os membros da comunidade podem catar os pequis nas propriedades dos outros somente para o consumo. Em Campo Azul, as propriedades camponesas são maiores e a propriedade fundiária influencia diretamente no sistema comunitário de coleta do pequi. Este foi o único município onde encontramos o arrendamento das terras e a meação da coleta de pequi, que são formas de se extrair a renda da terra. Assim, temos a lógica do dinheiro e do capital impondo-se sobre a lógica costumeira, sem eliminá-la, porém transformando-a.

Além dos aspectos materiais, reconhecidos pela sua intensa dinâmica econômica, o pequi tem grande impacto na vida cultural e simbólica de toda a população sertaneja. Pela sua relevância material e simbólica, o pequi e o pequizeiro podem ser considerados patrimônios culturais sertanejos. Seus sabores e saberes podem ser registrados como patrimônio cultural imaterial sertanejo, a exemplo do óleo de 
pequi. Cabe também estimular a conservação dos pequizeiros evitando-se que os frutos sejam retirados da árvore antes de concluir sua maturação. Para isso, assegurar tal proteção em lei, consoante ocorreu em Japonvar, já é um passo inicial, buscando, portanto, um maior envolvimento da população local, a qual é a principal defensora atual do fruto e da árvore sertanejos.

\section{Referências}

ABREU, Regina. A emergência do patrimônio genético e a nova configuração do campo do patrimônio. In: ABREU, R.; CHAGAS, M. (Org.). Memória e patrimônio: ensaios contemporâneos. Rio de Janeiro: DP\&A, 2003. p. 30-45.

ABREU, Regina; CHAGAS, Mário. Introdução. In: ABREU, R.; CHAGAS, M. (Org.). Memória e patrimônio: ensaios contemporâneos. Rio de Janeiro: DP\&A, 2003. p. 1218.

DELPHIM, Carlos Fernando de Moura. O patrimônio natural no Brasil. Rio de Janeiro: IPHAN, 2004. p. 1-20.

DEMATTEIS, Giuseppe. Apresentação - O território: uma oportunidade para repensar a Geografia. In: SAQUET, Marcos Aurélio. Abordagens e concepções de território. São Paulo: Expressão Popular, 2007. p. 7-11.

DIEGUES, Antônio Carlos. Repensando e recriando as formas de apropriação comum dos espaços e recursos naturais. In: DIEGUES, A. C. S.; MOREIRA, A. C. C. (Org.). Espaços e recursos naturais de uso comum. São Paulo: NUPAUB/USP, 2001. p. 97124.

FENNY, D. et al. A tragédia dos comuns: vinte e dois anos depois. In: DIEGUES, A. C. S.; MOREIRA, A. C. C. (Org.). Espaços e recursos naturais de uso comum. São Paulo: NUPAUB/USP, 2001. p. 17-42.

FONSECA, Maria Cecília Londres. Para além da pedra e cal: por uma concepção ampla de patrimônio cultural. In: ABREU, R.; CHAGAS, M. (Org.). Memória e patrimônio: ensaios contemporâneos. Rio de Janeiro: DP\&A, 2003. p. 56-76.

GOLDMAN, Michael. Inventando os Comuns: teorias e práticas do profissional em bens comuns. In: DIEGUES, A. C. S.; MOREIRA, A. C. C. (Org.). Espaços e recursos naturais de uso comum. São Paulo: NUPAUB/USP, 2001. p. 43-78.

GONÇALVES, José Reginaldo Santos. O patrimônio como categoria de pensamento. In: ABREU, R.; CHAGAS, M. (Org.). Memória e patrimônio: ensaios contemporâneos. Rio de Janeiro: DP\&A, 2003. p. 22-29. 
HARDIN, Garret J. The Tragedy of the Commons. Science. v. 162, n. 3859, p. 12431248, dez. 1968.

JAPONVAR. Lei Municipal $n^{\circ}$ 96, de janeiro de 2004, dispõe sobre proibição de colheita antecipada dos frutos do Pequizeiro e dá outras providências. Prefeitura Municipal de Japonvar, Japonvar, 12 nov. 2003.

MACEDO, João Faria. Pequi: do plantio à mesa. Belo Horizonte: EPAMIG, 2005. 44 p. (Boletim Técnico; 76).

MCKEAN, Margaret A.; OSTROM, Elinor. Regimes de propriedade comum em florestas: somente uma relíquia do passado? In: DIEGUES, A. C. S.; MOREIRA, A. C. C. (Org.). Espaços e recursos naturais de uso comum. São Paulo: NUPAUB/USP, 2001. p. 79-96.

MINAS GERAIS. Lei $\mathrm{n}^{\circ}$ 13.965, de 27 de julho de 2001. Cria o Programa Mineiro de Incentivo ao Cultivo, à Extração, ao Consumo, à Comercialização e à Transformação do Pequi e demais Frutos e Produtos Nativos do Cerrado - PRÓ-PEQUI. Minas Gerais, Belo Horizonte, 28 jul. 2001. Disponível em: <http://www.almg.gov.br>. Acesso em: 05 maio 2011.

MOURA, Margarida Maria. Camponeses. São Paulo: Ática, 1986. 78 p. (Série Princípios).

OLIVEN, Ruben George. Patrimônio intangível: considerações iniciais. In: ABREU, R.; CHAGAS, M. (Org.). Memória e patrimônio: ensaios contemporâneos. Rio de Janeiro: DP\&A, 2003. p. 77-80.

SANTOS, MILTON. O dinheiro e o território. In: SANTOS, Milton et al. Território, territórios: ensaios sobre o ordenamento territorial. 2. ed. Rio de Janeiro: DP\&A, 2006. p. 13-21.

SERRANO, Célia. Patrimônio, natureza e cultura: uma introdução a olhares e práticas. In: PAES-LUCHIARI, M. T.; BRUHNS, H. T.; SERRANO, C. (Org.). Patrimônio, natureza e cultura. Campinas: Papirus, 2007. p. 9-21.

THOMPSON, E. P. Costumes em comum. São Paulo: Companhia da Letras, 1998. 493 p.

Artigo recebido para publicação em jan/14

Artigo aceito para publicação em maio/14 